\title{
(2) OPEN ACCESS \\ Clinical academic leadership in COVID-19: a rapid response to sharing emerging insights in intensive care
}

\author{
Nirandeep Rehill, ${ }^{1,2}$ Amanda Begley, ${ }^{1}$ Katie Mantell, ${ }^{1}$ C Michael Roberts ${ }^{1}$
}

\begin{abstract}
'UCL Partners, London, UK ${ }^{2}$ NIHR Applied Health Research North Thames, London, UK
\end{abstract}

\section{Correspondence to} Dr Amanda Begley, UCL Partners, London W1T 7HA, UK; amanda.begley@uclpartners. com

Received 18 May 2020 Revised 9 June 2020

Accepted 11 June 2020 Published Online First 1 July 2020
Check for updates

(C) Author(s) (or their employer(s)) 2020. Re-use permitted under CC BY-NC. No commercial re-use. See rights and permissions. Published by BMJ.

To cite: Rehill N, Begley A, Mantell $\mathrm{K}$, et al. BMJ Leader 2020:4:228-230.

\begin{abstract}
Background The COVID-19 pandemic has raised a wide range of challenges for health systems around the world and the National Health Service in England has been no exception. A significant proportion of infected cases require intensive care unit support and have a high mortality rate. In the early stages of the pandemic, there was neither an evidence base nor a clinical consensus on the optimal management of patients in this setting. Interventions Responding to requests for assistance to address this evidence gap, UCLPartners, an Academic Health Science Partnership, working in collaboration with other organisations including National Institute of Health Research Applied Research Collaboration North Thames, developed a clinical academic team to synthesise clinical learning in real time. This was then disseminated using existing networks and social media to local, regional, national and international clinical teams.

Conclusion An Academic Health Science Partnership was able to respond quickly through adapting and expediting traditional methods of evidence gathering, supporting organisations to work collaboratively across their networks and so meet an urgent clinical need to the benefit of clinicians and patients.
\end{abstract}

\section{INTRODUCTION}

As the COVID-19 pandemic gained a foothold in the UK, the pressure was acute-within 8 days in late March 2020 hospital deaths from COVID rose 10 -fold from 35 to 374 a day. ${ }^{1}$ Much of this pressure was on intensive care units (ICU), receiving $5 \%{ }^{2}$ of people infected with severe acute respiratory syndrome coronavirus 2 who developed a form of adult respiratory distress syndrome (ARDS) requiring ventilatory support.

Early reports revealed a mortality rate of c.50\% in that group. ${ }^{34}$ ICU clinicians were in urgent need of guidance; however, guidelines rely heavily on both research-based evidence and clinical consensus. The pandemic had erupted at such pace that neither were available for COVID-19. The system responded with the publication of international guidelines drawn from the evidence for the treatment of (non-COVID) viral pneumonia and ARDS, including surviving sepsis guidelines ${ }^{5}$ and National Institute for Health and Care Excellence guidance on critical care escalation. ${ }^{6}$

At such moments, there is a need for a different type of leadership where responsiveness, challenge to convention and support to clinical leaders are key. UCLPartners, an Academic Health Science Partnership, was one organisation in a position to assume that role. UCLPartners is a partnership of 23 National Health Service (NHS) trusts and 9 higher education institutions covering north central and east London and parts of Essex, Hertfordshire and Bedfordshire. Governed by a partnership board and led by clinical academics supported by a corporate senior team, its purpose is to bring together organisations to work collaboratively for the health and care of the population served.

\section{SHARING EMERGING INSIGHTS}

Through our partnership, we received intelligence that clinicians were concerned that the traditional management of ARDS and other complications was not having expected outcomes against this novel disease - and that emerging knowledge and experience needed to be shared to inform care. Our independence and clinical academic connections put us in a position to take up leadership responsibility to rapidly fill this gap, allowing us to avoid the bureaucratic processes embedded in central bodies. We illustrate our response in figure 1 and a description in this section of three related interventions.

\section{The Nightingale learning health system}

The London Nightingale was a 'pop-up hospital' designed to accommodate up to 3000 ICU patients and was incorporated into the governance structure of a partner NHS trust. UCLPartners was to help ensure that clinical care would be informed by the most recent evidence and best practice. We deployed staff on site to establish an 'internal learning system', involving daily review of clinical data and insights, supported by a new role of Bedside Learning Coordinator. Learning was summarised into 'bite-sized' presentations given at daily staff briefings, at which clinical teams were able to raise questions requiring urgent response.

In parallel, UCLPartners established an 'external learning system' forming a team of clinical, academic, programme management and communications experts. This system was both reactiverapidly responding to front-line queries-and proactive in producing weekly highlights of published literature alongside emerging qualitative insights from research underway on COVID-19. These highlights included short summaries designed for pressured clinical teams and aimed to highlight 3-5 key actionable insights.

Over 5 weeks, 13 questions were raised relating to clinical presentation (eg, coagulopathy, delirium), clinical management (eg, drug side-effects, Endotracheal Tube blockages), infection control (eg, 


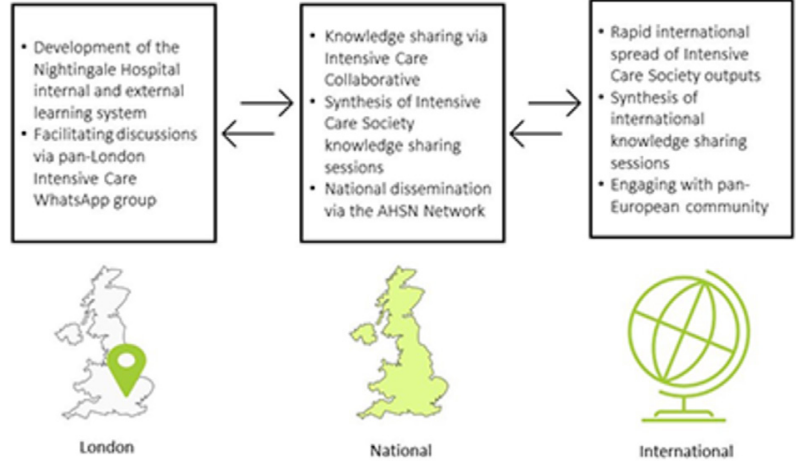

Figure 1 Overview of interventions within UCLPartners intensive care programme including target audience. AHSN, Academic Health Science Network.

Continuous Positive Airway Pressure) and staff well-being (eg, dehydration, shift patterns).

\section{The Intensive Care Society (ICS) collaboration}

The ICS is the professional society representing clinicians working in intensive care in the UK. Early indications showed clinicians were struggling to manage a condition that did not appear to adhere to the principles of ARDS or previous viral pneumonias and had much higher mortality. The society planned to hold a series of webinars to collate emerging clinical experience and synthesise learning in close to real time. UCLPartners was approached to provide academic support, via its partner National Institute of Health Research Applied Research Collaboration North Thames, to synthesise the learning and to use its communications expertise to present this in a format suitable for wider dissemination to front-line clinicians. Seven webinars involving hundreds of participants were held across a range of topics, engaging clinicians from across the world.

\section{ICU collaborative}

In recognition of the need to rapidly share learning, UCLPartners established a virtual learning platform to facilitate multidisciplinary, multispecialty discussions, initially in partnership with London Academic Health Science Networks (AHSNs), followed by expansion nationally. The virtual collaborative provided a mechanism to disseminate insights generated through work with the Nightingale and ICS, and enables clinicians to share their experiences, highlight challenges and seek advice. A clinical moderator was appointed to facilitate discussion and synthesise the learning emerging in the online discussions. Within 3 weeks of the platform being initially promoted, 44 members had joined. An associated WhatsApp group was formed to ensure front-line staff rapidly received updates and could raise questions.

\section{Impact}

Thus far, we have produced 12 COVID-19 reports which-by drawing on clinical insights alongside grey and published literature-have responded to questions and topics raised by ICU staff including: syntheses of clinical experiences in UK and international intensive care settings; thromboprophylaxis and anticoagulation of ICU patients; review of coronavirus autopsy reports globally regarding pathophysiology and complications of COVID.

The reports have been shared widely though regional, national and international networks. In England, the country's 15 AHSNs have provided a route for rapid dissemination to front-line ICU teams within their regions. The resources were shared via email with more than 5000 contacts in the UK-wide ICS community, and were engaged with widely on Twitter (296000 impressions; more than 7000 engagements) and Facebook (more than 1600 likes and shares). They were also distributed to more than 250 UK-wide COVID-19 leads on the ICS/Faculty of Intensive Care Management Whatsapp group, and shared with members of the UK Scientific Advisory Group for Emergencies committee.

The emerging learning was spontaneously shared by clinicians across social media and WhatsApp groups, receiving hundreds of comments of thanks.

The reach has been global: the WHO joined ICS webinars, and we were told Professor Don Berwick had welcomed the resources and would share them with ICUs in the USA.

\section{LEADERSHIP LEARNING}

Taking on the role of sharing emerging insights during COVID-19 revealed some core elements of leadership, which may be applicable to other situations requiring rapid learning.

\section{Responsiveness}

When the pandemic first hit the NHS, clinicians and leaders reported being overwhelmed by the unknowns of how to respond. At a time when staff most needed to reach out to peers, to scan the literature, to digest official guidance, they were hit with unprecedented volumes of critically ill patients.

Within a week, we started producing daily outputs, followed by weekly reports on emerging evidence; we were highly responsive to daily queries.

To deliver this support we found ourselves, as highlighted by Sadler and Stewart, ${ }^{7}$ needing to 'throw away [our] calendar, act with intense urgency, own the problem and form a crisis management team'. Rapid decision-making by the senior leadership team allowed UCLPartners to flex from its business as usual to form a new team to address the problem within days of the ask.

\section{Joining up leadership is key}

The challenge in a time of crisis is not lack of leadership but lack of joined-up leadership. Reflecting on the 2017 terrorist attacks in Manchester, UK, Lord Kerslake advised leaders to 'consider how the differing cultures of all the organisations involved in a major incident might prove an obstacle to collaboration and how that might be overcome'. ${ }^{8}$

To facilitate rapid impact, our role was to join up those leaders in need of support: clinical leaders at the Nightingale Hospital, wider clinical teams across the London region and organisational leaders as in the ICS. The ICS brought brand strength and professional oversight alongside an immediate UK-wide clinical network for dissemination, while the UCLPartners brand lent credibility to those with an understanding of the Academic Health Science Centre model. Our collaboration with AHSNs enabled a wider reach through an established national network.

\section{Challenging the process: courage and risk-taking}

When the established system could not meet the need, challenge to the process, as described by Kouzes and Posner, ${ }^{9}$ was required. Implicit are courage and risk-taking to share emerging insights that under normal circumstances would require closer scrutiny and a higher burden of proof. Our courage came from the demand-the questions received, the cognitive overload and the mortality rates. We were convinced of the gap between what clinicians needed (emerging evidence and rapidly created guidance) and what risk-averse national institutions were willing 
to provide at speed. Mitigating that risk by triangulating clinical experience across sites, sense checking with independent academics, comparing with the grey literature and emerging peer-reviewed publications was a key assurance process that provided greater confidence in these outputs.

Social media has transformed how real time insights are rapidly spread at scale. Dissemination has been spontaneous and organic rather than planned. In leadership terms, there is a need to let go of some control and let expert clinicians share what is useful to them. The responsibility for critical appraisal and quality control remains, as social media is also a mechanism through which misinformation can be rapidly disseminated. ${ }^{10}$

\section{CONCLUSION}

In a situation where conventional resources to guide clinical management are unavailable, there is a need to act quickly, challenging the system and establishing new methods outside the usual parameters of risk and validation in order to document and disseminate knowledge in real time. An Academic Health Science Partnership has that ability to react and support at scale and pace without the confines of centralised institutional bureaucracy.

\section{Twitter Amanda Begley @UCLPartners}

Acknowledgements With thanks to Hugh Montgomery and Sandy Mayer, Intensive Care Society for organising and hosting the webinars; Shruti Dholakia, Laura Haywood, Natalie Elkheir, Catherine Huntley, Leanne Aitken, Morgan McKean and Rosalind Raine for supporting the Nightingale 'external learning system'; Jenny Shand and Rebecca Graham, UCLPartners, deployed to support the set-up of London Nightingale; Morgan McKean, Aman Gupta, Sophie Bulmer and Lynsey Shevlin, UCLPartners, for coordinating and supporting delivery of the intensive care collaborative; Figure 1 is an adaption of a slide developed by Morgan McKean, UCLPartners.

Contributors NR led on academic responses to front-line queries and weekly evidence summaries; synthesised the ICS webinar discussions; drafted and revised the paper. AB programme managed UCLPartners' intensive care programme; led the development of the IC collaborative; drafted and revised the paper. KM led UCLPartners' intensive care programme communications and engagement work; drafted and revised the paper. CMR led UCLPartners' intensive care programme; drafted and revised the paper.
Funding NR is part-funded by the National Institute for Health Research (NIHR Applied Research Collaboration North Thames).

Disclaimer The views expressed are those of the author(s) and not necessarily those of the NHS, the NIHR or the Department of Health and Social Care.

Competing interests None declared.

Patient consent for publication Not required.

Provenance and peer review Not commissioned; externally peer reviewed.

Open access This is an open access article distributed in accordance with the Creative Commons Attribution Non Commercial (CC BY-NC 4.0) license, which permits others to distribute, remix, adapt, build upon this work non-commercially, and license their derivative works on different terms, provided the original work is properly cited, appropriate credit is given, any changes made indicated, and the use is non-commercial. See: http://creativecommons.org/licenses/by-nc/4.0/.

\section{REFERENCES}

1 Coronavirus (COVID-19) in the UK. Available: https://coronavirus.data.gov.uk/ [Accessed Mar 2020].

2 Wu Z, McGoogan JM. Characteristics of and important lessons from the coronavirus disease 2019 (COVID-19) outbreak in China. JAMA 2020;323:1239-42.

3 ICNARC report on COVID-19 in critical care 08 may 2020. Available: https://www. icnarc.org/DataServices/Attachments/Download/b8c18e7d-e791-ea11-912500505601089b [Accessed May 2020].

4 Piva S, Filippini M, Turla F, et al. Clinical presentation and initial management critically ill patients with severe acute respiratory syndrome coronavirus 2 (SARS-CoV-2) infection in Brescia, Italy. J Crit Care 2020;58:29-33.

5 Alhazzani W, Møller MH, Arabi YM, et al. Surviving sepsis campaign: guidelines on the management of critically ill adults with coronavirus disease 2019 (COVID-19). Crit Care Med 2020;48:e440-69.

6 National Institute for Health and Care Excellence. COVID-19 rapid guideline: critical care in adults. NICE 2020 (NICE guideline [NG159]). Available: https://www.nice.org. uk/guidance/ng159

7 Sadler BL, Stewart K. Leading in a crisis: the power of transparency. London: The Health Foundation, 2015

8 NHS Confederation. When tragedy strikes reflections on the NHS response to the Manchester arena bombing and Grenfell tower fire. London: NHS Confederation, 2018.

9 Kouzes J, Posner B. The leadership challenge: how to make extraordinary things happen in organizations. 5th edn. Chichester: John Wiley and Sons Ltd, 2012.

10 Maheswaran Y. Medical professionals must remain vigilant to the dangers of misinformation. BMJ opinion, 2020. Available: https://blogs.bmj.com/bmj/2020/05/ 11/yathukulan-maheswaran-medical-professionals-must-remain-vigilant-to-thedangers-of-misinformation/ 